\title{
Biodegradable blends of starch/polyvinyl alcohol/glycerol: multivariate analysis of the mechanical properties
}

\author{
Juliano Zanela ${ }^{1,2 *}$, Maira Casagrande ${ }^{2}$, Marianne Ayumi Shirai ${ }^{3}$, Vanderlei Aparecido de Lima ${ }^{4}$ \\ and Fabio Yamashita ${ }^{1}$
${ }^{1}$ Department of Food Science and Technology, Universidade Estadual de Londrina - UEL, Londrina, PR, Brazil \\ ${ }^{2}$ Universidade Tecnológica Federal do Paraná - UTFPR, Dois Vizinhos, PR, Brazil \\ ${ }^{3}$ Universidade Tecnológica Federal do Paraná - UTFPR, Londrina, PR, Brazil \\ ${ }^{4}$ Universidade Tecnológica Federal do Paraná - UTFPR, Pato Branco, PR, Brazil \\ *julianozanela@gmail.com
}

\begin{abstract}
The aim of the work was to study the mechanical properties of extruded starch/polyvinyl alcohol (PVA)/glycerol biodegradable blends using multivariate analysis. The blends were produced as cylindrical strands by extrusion using PVAs with different hydrolysis degrees and viscosities, at two extrusion temperature profiles $\left(90 / 170 / 170 / 170 / 170{ }^{\circ} \mathrm{C}\right.$ and $90 / 170 / 200 / 200 / 200{ }^{\circ} \mathrm{C}$ ) and three conditioning relative humidities of the samples (33, 53, and 75\%). The mechanical properties showed a great variability according to PVA type, as well as the extrusion temperature profile and the conditioning relative humidity; the tensile strength ranged from 0.42 to $5.40 \mathrm{MPa}$, elongation at break ranged from 10 to $404 \%$ and Young's modulus ranged from 0.93 to $13.81 \mathrm{MPa}$. The multivariate analysis was a useful methodology to study the mechanical properties behavior of starch/PVA/glycerol blends, and it can be used as an exploratory technique to select of the more suitable PVA type and extrusion temperature to produce biodegradable materials.
\end{abstract}

Keywords: biodegradable material, extrusion, principal component analysis.

\section{Introduction}

The environmental concerns about the plastic wastes are increasing, promoting the development of suitable alternatives for petroleum based polymers, and starch is a promisor biopolymer from renewable resources to produce biodegradable materials. However, the mechanical properties of these materials are poor, being necessary the development of blends with others biodegradable polymers to improve its mechanical and barrier properties.

Polyvinyl alcohol (PVA) is a biodegradable polymer with vast use in paper and textile industry; it is available industrially with several hydrolysis degree and molecular weight, and these characteristics can affect the properties of the materials produced with PVA blends ${ }^{[1,2]}$, and PVA can be processed by thermoplastic extrusion ${ }^{[3]}$.

Blending starch with polyvinyl alcohol (PVA) can improve the mechanical properties and maintain the biodegradability of starch-based materials how observed in many works ${ }^{[4-7]}$.

To produce biodegradable material by extrusion it is necessary to extrude the blend components producing cylindrical strands, to pelletize the strands, and then to extrude these pellets to produce the material by blown extrusion or flat die extrusion-calendering process. According to Nobrega et al. ${ }^{[8]}$, the mechanical and viscoelastic properties of extruded cylindrical strands from biodegradable polymer blends (starch/poly (butylene adipate co-terephthalate)/ glycerol) were correlated with their capacity to form films by blown extrusion process.
The aim of this work was to study the behavior of the mechanical properties of starch/polyvinyl alcohol/glycerol blends using multivariate analysis. The blends were produced as cylindrical strands by extrusion with different polyvinyl alcohol types, and extrusion temperature profiles.

\section{Materials and Methods}

\section{1 Materials}

The polyvinyl alcohol (PVA) with different degree of hydrolysis (DH) and viscosities (4\% aqueous solution) were provided by Sekisui Chemical (Japan): SelvolTM 203 (DH: 88.14\%, viscosity: 4.10 cP); Selvol ${ }^{\mathrm{TM}} 523$ (DH: 87.84\%, viscosity: $24.50 \mathrm{cP}$ ); Selvol ${ }^{\mathrm{TM}} 540$ (DH: $88.04 \%$, viscosity: $49.40 \mathrm{cP}$ ); Selvol ${ }^{\mathrm{TM}} 107$ (DH: $98.30 \%$, viscosity: $6.00 \mathrm{cP}$ ) and Selvol ${ }^{\mathrm{TM}} 325$ (DH: $98.42 \%$, viscosity: $\left.31.40 \mathrm{cP}\right)$. The native cassava starch was provided by Indemil (Brazil) and the technical grade glycerol by Dinamica (Brazil).

\subsection{Cylindrical strands production}

The PVA, starch, and glycerol (20:40:40\% w/w) were manually homogenized and conditioned in vacuum oven (model Q819V2, Quimis, Brazil) with a vacuum pressure of $0.085 \mathrm{MPa}$ for $90 \mathrm{~min}$ at $85^{\circ} \mathrm{C}$ to incorporate the glycerol, according the method adapted from Jang and Lee ${ }^{[9]}$. The blends were extruded in a co-rotating twin-screw extruder (model D-20, BGM, Brazil) with a six holes $(2 \mathrm{~mm})$ die to produce the cylindrical strands, and a screw diameter of $20 \mathrm{~mm}(\mathrm{~L} / \mathrm{D}=35)$. 
The screw speed was set at $100 \mathrm{rpm}$ and it was used two extrusion temperature profiles: $90 / 170 / 170 / 170 / 170{ }^{\circ} \mathrm{C}$ and $90 / 170 / 200 / 200 / 200{ }^{\circ} \mathrm{C}$, totaling 10 different formulations (5 PVA types $\mathrm{x} 2$ extrusion temperature profiles).

\subsection{Mechanical characterization}

The tensile strength, Young's modulus and elongation at break tests were performed according to ASTM D882-02 $2^{[10]}$ using a texture analyzer (model TA.XT2i, Stable Micro Systems, England) with an initial distance between grips of $30 \mathrm{~mm}$ and a crosshead speed of $0.8 \mathrm{~mm} / \mathrm{s}$.

Ten samples from each treatment (50 $\mathrm{mm}$ in length) were conditioned at different relative humidity $(33 \pm 2 \%, 53 \pm 2 \%$, and $75 \pm 2 \% \mathrm{RH}$ ) for 72 hours at $23 \pm 2{ }^{\circ} \mathrm{C}$ before analysis.

\subsection{Statistical analyses}

The multivariate exploratory techniques, Principal Components Analysis (PCA) and Hierarchical Cluster Analysis, were performed using STATISTICA 7.0 software (Statsoft, USA). For PCA, the mechanical parameters (tensile strength, Young's modulus, and elongation at break) were used as active variables in the derivation of the principal components, and the supplementary variables (temperature, hydrolysis degree, viscosity, and relative humidity) were projected onto the factor space. The PCA analysis was performed using the covariance matrix. The hierarchical tree was obtained considering the same active variables applied to PCA. The formulations were joined by single linkage as linkage rule, and considering the Euclidean distance as the coefficient of similarity

\section{Results and Discussions}

The results of the cylindrical strands mechanical properties are presented in Table 1. Tensile strength ranged from 0.42 to $5.40 \mathrm{MPa}$, elongation at break ranged from 10 to $404 \%$ and Young's modulus ranged from 0.93 to $13.81 \mathrm{MPa}$, showing a great variability according to PVA type, as well as the extrusion temperature profile and the conditioning relative humidity.

The Figure 1a presents the Principal Component Analysis (PCA) plot of active and supplementary variables for mechanical properties of cylindrical strands, and is possible to observe that the two principal components explained $97.28 \%$ of total variance.

The tensile strength was positively correlated with the extrusion temperature profile, probably because the extrusion

Table 1. Mechanical properties of PVA/starch/glycerol cylindrical strands.

\begin{tabular}{|c|c|c|c|c|c|}
\hline PVA & $\begin{array}{l}\text { Extrusion Temperature Profile } \\
\qquad\left({ }^{\circ} \mathrm{C}\right)\end{array}$ & $\begin{array}{c}\text { Relative Humidity } \\
(\%)\end{array}$ & $\begin{array}{l}\text { Tensile Strength } \\
\text { (MPa) }\end{array}$ & $\begin{array}{c}\text { Elongation at Break } \\
\qquad(\%)\end{array}$ & $\begin{array}{c}\text { Young's Modulus } \\
\text { (MPa) }\end{array}$ \\
\hline \multirow{6}{*}{ Selvol 203} & \multirow{3}{*}{$90 / 170 / 170 / 170 / 170{ }^{\circ} \mathrm{C}$} & $33 \%$ & $1.44 \pm 0.11$ & $61 \pm 7$ & $5.46 \pm 0.37$ \\
\hline & & $53 \%$ & $0.83 \pm 0.16$ & $32 \pm 5$ & $4.09 \pm 0.75$ \\
\hline & & $75 \%$ & $0.60 \pm 0.25$ & $10 \pm 4$ & $0.93 \pm 0.60$ \\
\hline & \multirow{3}{*}{$90 / 170 / 200 / 200 / 200^{\circ} \mathrm{C}$} & $33 \%$ & $1.38 \pm 0.20$ & $92 \pm 14$ & $4.4 \pm 0.72$ \\
\hline & & $53 \%$ & $0.72 \pm 0.10$ & $41 \pm 12$ & $3.11 \pm 0.38$ \\
\hline & & $75 \%$ & $0.42 \pm 0.06$ & $39 \pm 6$ & $2.50 \pm 0.38$ \\
\hline \multirow{6}{*}{ Selvol 523} & \multirow{3}{*}{$90 / 170 / 170 / 170 / 170{ }^{\circ} \mathrm{C}$} & $33 \%$ & $2.20 \pm 0.34$ & $166 \pm 48$ & $5.25 \pm 0.91$ \\
\hline & & $53 \%$ & $2.39 \pm 0.48$ & $186 \pm 47$ & $5.40 \pm 1.07$ \\
\hline & & $75 \%$ & $1.12 \pm 0.43$ & $155 \pm 94$ & $2.48 \pm 0.54$ \\
\hline & \multirow{3}{*}{$90 / 170 / 200 / 200 / 200^{\circ} \mathrm{C}$} & $33 \%$ & $4.56 \pm 0.79$ & $391 \pm 91$ & $7.97 \pm 0.71$ \\
\hline & & $53 \%$ & $2.77 \pm 0.40$ & $404 \pm 95$ & $4.84 \pm 0.35$ \\
\hline & & $75 \%$ & $1.78 \pm 0.19$ & $347 \pm 85$ & $3.38 \pm 0.89$ \\
\hline \multirow{6}{*}{ Selvol 540} & \multirow{3}{*}{$90 / 170 / 170 / 170 / 170{ }^{\circ} \mathrm{C}$} & $33 \%$ & $1.46 \pm 0.17$ & $119 \pm 22$ & $2.64 \pm 0.61$ \\
\hline & & $53 \%$ & $0.95 \pm 0.18$ & $108 \pm 32$ & $1.88 \pm 0.49$ \\
\hline & & $75 \%$ & $1.18 \pm 0.23$ & $86 \pm 15$ & $2.60 \pm 0.88$ \\
\hline & \multirow{3}{*}{$90 / 170 / 200 / 200 / 200^{\circ} \mathrm{C}$} & $33 \%$ & $2.46 \pm 0.35$ & $149 \pm 35$ & $5.27 \pm 0.70$ \\
\hline & & $53 \%$ & $1.83 \pm 0.25$ & $136 \pm 27$ & $4.05 \pm 0.42$ \\
\hline & & $75 \%$ & $1.41 \pm 0.37$ & $131 \pm 24$ & $2.84 \pm 0.81$ \\
\hline \multirow{6}{*}{ Selvol 107} & \multirow{3}{*}{$90 / 170 / 170 / 170 / 170{ }^{\circ} \mathrm{C}$} & $33 \%$ & $1.67 \pm 0.23$ & $62 \pm 16$ & $7.60 \pm 0.52$ \\
\hline & & $53 \%$ & $1.28 \pm 0.25$ & $47 \pm 6$ & $6.58 \pm 0.97$ \\
\hline & & $75 \%$ & $0.82 \pm 0.08$ & $39 \pm 12$ & $4.33 \pm 0.75$ \\
\hline & \multirow{3}{*}{$90 / 170 / 200 / 200 / 200^{\circ} \mathrm{C}$} & $33 \%$ & $2.57 \pm 0.15$ & $95 \pm 16$ & $13.30 \pm 0.93$ \\
\hline & & $53 \%$ & $1.52 \pm 0.11$ & $52 \pm 8$ & $9.56 \pm 0.71$ \\
\hline & & $75 \%$ & $1.40 \pm 0.11$ & $98 \pm 17$ & $8.35 \pm 0.95$ \\
\hline \multirow{6}{*}{ Selvol 325} & \multirow{3}{*}{$90 / 170 / 170 / 170 / 170^{\circ} \mathrm{C}$} & $33 \%$ & $1.90 \pm 0.21$ & $83 \pm 14$ & $5.79 \pm 0.74$ \\
\hline & & $53 \%$ & $1.49 \pm 0.19$ & $81 \pm 16$ & $4.18 \pm 0.64$ \\
\hline & & $75 \%$ & $1.40 \pm 0.14$ & $81 \pm 16$ & $4.18 \pm 0.39$ \\
\hline & \multirow{3}{*}{$90 / 170 / 200 / 200 / 200^{\circ} \mathrm{C}$} & $33 \%$ & $5.40 \pm 0.58$ & $262 \pm 24$ & $13.81 \pm 1.57$ \\
\hline & & $53 \%$ & $4.06 \pm 0.52$ & $219 \pm 47$ & $11.63 \pm 1.63$ \\
\hline & & $75 \%$ & $3.47 \pm 0.47$ & $236 \pm 88$ & $9.03 \pm 1.12$ \\
\hline
\end{tabular}


process was more efficient at the higher temperature profile, permitting a better interaction among the components (starch/PVA/glycerol).

The PVA hydrolysis degree correlated well with Young's modulus, probably because the higher the hydrolysis degree the higher the number of hydroxyl groups in substitution of the acetate groups, enabling more interactions by hydrogen bonds with starch molecules, so increasing their rigidity. The PVA viscosity correlated well with the elongation at break of the strands, probably because the longer PVA chains.

The conditioning relative humidity had a negative correlation with the mechanical properties, due to the
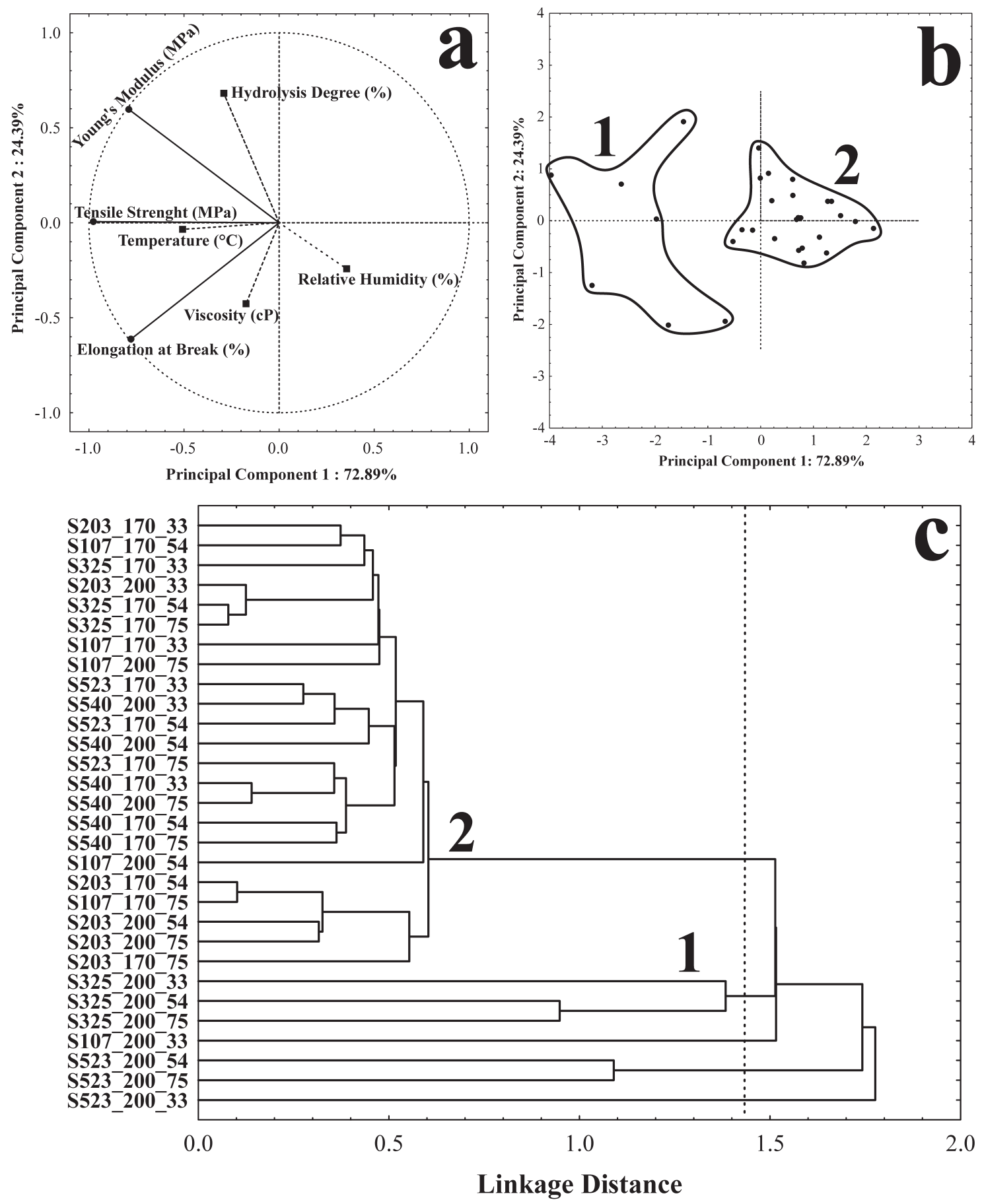

Figure 1. Classification of the formulations by mechanical parameters. (a) Variable projection by PCA: - active variable, -----supplementary variable; (b) Scatterplot for the formulations by PCA with grouping suggested by HCA; and (c) Dendogram by HCA analysis with the separation in two distinct clusters (1 and 2). 
hydrophilic characteristic of starch/PVA-based materials. The water acts as plasticizer, consequently materials conditioned at high RH absorb more water, decreasing their mechanical properties ${ }^{[11,12]}$.

In the scatterplot (Figure 1b), the samples could be grouped in two distinct clusters considering the groups suggested by the dendogram of the hierarchical cluster analysis (Figure 1c). The cluster ' 1 ' is composed by the strands produced with Selvol 523 and 325 at the higher extrusion temperature profile $\left(90 / 170 / 200 / 200 / 200{ }^{\circ} \mathrm{C}\right)$ and the three conditioning relative humidities $(33,53$ and $75 \% \mathrm{RH})$, and with Selvol 107 at the higher temperature profile and 33\% $\mathrm{RH}$. The cluster ' 2 ' is composed by the remaining strands (below the cutting line of the dendogram) based in their similarities.

According to the dendogram, the higher extrusion temperature profile was more adequate for extrusion process of PVA, and PVA with medium chain size (Selvol 325 Selvol 523 ) resulted in materials with better mechanical properties.

\section{Conclusions}

The multivariate analysis was a useful methodology to study the mechanical properties behavior of starch/PVA/glycerol blends, and it can be used as an exploratory technique to select of the more suitable PVA type and extrusion temperature to produce biodegradable materials. The PVA with medium chain size, independently of their hydrolysis degree (Selvol 325 and 523), presented the more adequate mechanical properties, and they are promising polymers for future studies.

\section{Acknowledgements}

The authors thank the Federal Technological University of Paraná (Universidade Tecnológica Federal do Paraná - UTFPR), the National Council for Scientific and Technological Development (Conselho Nacional de Desenvolvimento Científico e Tecnológico - CNPq) and the Araucaria Foundation (Fundação Araucaria) for their financial support.

\section{References}

1. Limpan, N., Prodpran, T., Benjakul, S., \& Prasarpran, S. (2012). Influences of degree of hydrolysis and molecular weight of poly(vinyl alcohol) (PVA) on properties of fish myofibrillar protein/PVA blend films. Food Hydrocolloids, 29(1), 226-233. http://dx.doi.org/10.1016/j.foodhyd.2012.03.007.
2. Maria, T. M. C., de Carvalho, R., Sobral, P. J. A., Habitante, A. M. B. Q., \& Solorza-Feria, J. (2008). The effect of the degree of hydrolysis of the PVA and the plasticizer concentration on the color, opacity, and thermal and mechanical properties of films based on PVA and gelatin blends. Journal of Food Engineering, 87(2), 191-199. http://dx.doi.org/10.1016/j. jfoodeng.2007.11.026.

3. Tang, X., \& Alavi, S. (2011). Recent advances in starch, polyvinyl alcohol based polymer blends, nanocomposites and their biodegradability. Carbohydrate Polymers, 85(1), 7-16. http://dx.doi.org/10.1016/j.carbpol.2011.01.030.

4. Zanela, J., Olivato, J. B., Dias, A. P., Grossmann, M. V. E., \& Yamashita, F. (2015). Mixture design applied for the development of films based on starch, polyvinyl alcohol, and glycerol. Journal of Applied Polymer Science, 132(43), 42697. http://dx.doi.org/10.1002/app.42697.

5. Sin, L. T., Rahman, W. A. W. A., Rahmat, A. R., \& Mokhtar, M. (2011). Determination of thermal stability and activation energy of polyvinyl alcohol-cassava starch blends. Carbohydrate Polymers, 83(1), 303-305. http://dx.doi.org/10.1016/j. carbpol.2010.07.049.

6. Tang, X., \& Alavi, S. (2012). Structure and physical properties of starch/poly vinyl alcohol/laponite RD nanocomposite films. Journal of Agricultural and Food Chemistry, 60(8), 1954-1962. http://dx.doi.org/10.1021/jf2024962. PMid:22217361.

7. Brandelero, R. P. H., Yamashita, F., Zanela, J., Brandelero, E. M., \& Caetano, J. G. (2015). Mixture design applied to evaluating the effects of polyvinyl alcohol (PVOH) and alginate on the properties of starch-based films. Stärke, 67(1-2), 191-199. http://dx.doi.org/10.1002/star.201400119.

8. Nobrega, M. M., Olivato, J. B., Bilck, A. P., Grossmann, M. V. E., \& Yamashita, F. (2012). Glycerol with different purity grades derived from biodiesel: Effect on the mechanical and viscoelastic properties of biodegradable strands and films. Materials Science and Engineering C, 32(8), 2220-2222. http:// dx.doi.org/10.1016/j.msec.2012.06.005.

9. Jang, J., \& Lee, D. K. (2003). Plasticizer effect on the melting and crystallization behavior of polyvinyl alcohol. Polymer, 44(26), 8139-8146. http://dx.doi.org/10.1016/j.polymer.2003.10.015.

10. American Standard Testing Methods - ASTM. (2002). D-88202: standard test methods for tensile properties of thin plastic sheeting. Philadelphia: ASTM. Annual book.

11. Mao, L., Imam, S., Gordon, S., Cinelli, P., \& Chiellini, E. (2002). Extruded cornstarch - glycerol - polyvinyl alcohol blends: mechanical properties, morphology, and biodegradability. Journal of Polymers and the Environment, 8(4), 1-7.

12. Chen, L., Imam, S. H., Gordon, S. H., \& Greene, R. V. (1997). Starch- polyvinyl alcohol crosslinked film: performance and biodegradation. Journal of Environmental Polymer Degradation, 5(2), 111-117. http://dx.doi.org/10.1007/BF02763594.

Received: Nov. 09, 2015

Accepted: June 21, 2016 